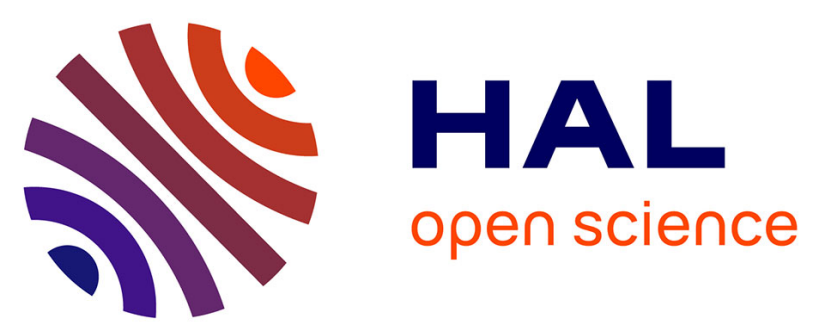

\title{
A wide-angle scanning switched-beam antenna system in LTCC technology with high beam crossing levels for V-band communications
}

Francesco Foglia Manzillo, Maciej Smierzchalski, Laurent Le Coq, Mauro Ettorre, Jouko Aurinsalo, Kari T Kautio, Markku Lahti, Antti E I Lamminen, Jussi Saily, Ronan Sauleau

\section{To cite this version:}

Francesco Foglia Manzillo, Maciej Smierzchalski, Laurent Le Coq, Mauro Ettorre, Jouko Aurinsalo, et al.. A wide-angle scanning switched-beam antenna system in LTCC technology with high beam crossing levels for V-band communications. IEEE Transactions on Antennas and Propagation, 2019, 67 (1), pp.541-553. 10.1109/TAP.2018.2877467 . hal-01952288

\section{HAL Id: hal-01952288}

\author{
https://hal-univ-rennes1.archives-ouvertes.fr/hal-01952288
}

Submitted on 12 Dec 2018

HAL is a multi-disciplinary open access archive for the deposit and dissemination of scientific research documents, whether they are published or not. The documents may come from teaching and research institutions in France or abroad, or from public or private research centers.
L'archive ouverte pluridisciplinaire HAL, est destinée au dépôt et à la diffusion de documents scientifiques de niveau recherche, publiés ou non, émanant des établissements d'enseignement et de recherche français ou étrangers, des laboratoires publics ou privés. 


\title{
A Wide-Angle Scanning Switched-Beam Antenna System in LTCC Technology with High Beam Crossing Levels for V-band Communications
}

\author{
Francesco Foglia Manzillo, Member, IEEE, Maciej Śmierzchalski, Laurent Le Coq, Mauro Ettorre, Senior \\ Member, IEEE, Jouko Aurinsalo, Kari T. Kautio, Markku S. Lahti, Antti E. I. Lamminen, Jussi Säily, and Ronan \\ Sauleau, Fellow, IEEE
}

\begin{abstract}
Wide-angle coverage, fine angular resolution and low-power consumption are key characteristics of millimeterwave (mm-wave) short-range wireless systems, such as access points in fifth-generation $(\mathbf{5 G})$ cellular networks and automotive radars. In this paper, we present a $60-\mathrm{GHz}$ switched-beam antenna system addressing all these requirements. It consists of two identical parallel-fed arrays of 8 slots, each fed by a passive pillbox beamformer. A switch network comprising four singlepole-multiple-throw (SPnT) switches excites one of the two arrays at a time and selects the radiated beam. The whole system is fully-integrated in a multilayer low temperature co-fired ceramic (LTCC) module. The antenna covers a scan range of about $\pm 39^{\circ}$ in one plane using eleven beams, between $57 \mathrm{GHz}$ and $66 \mathrm{GHz}$. The proposed architecture enables the simultaneous achievement of continuous coverage (beam crossover levels of about $-3 \mathrm{~dB}$ ) and of low sidelobe levels (SLLs). Dedicated numerical tools are used for a preliminary design of the antenna. The design procedure, the technological development and the experimental results are discussed in detail.
\end{abstract}

Index Terms-switched-beam antenna, millimeter-wave antennas, 5G, 60-GHz communications, low temperature co-fired ceramic (LTCC).

\section{INTRODUCTION}

$\mathbf{T}$ HE exploitation of the millimeter-wave (mm-wave) spectrum is essential to tackle the dizzying growth of mobile data traffic (10 000 fold by 2030 [1]) and to enhance the resolution of radar sensors. The unlicensed $57-66-\mathrm{GHz}$ band is particularly suited for high-throughput short-range communications, e.g. for access points in small cells (radius of less than $50 \mathrm{~m}$ ) with a high density of users [2]. Antennas with

F. Foglia Manzillo was with the Institute of Electronics and Telecommunications of Rennes (IETR), UMR CNRS 6164, University of Rennes 1, Rennes, France. He is currently with CEA-LETI, Minatec Campus, Grenoble, France (e-mail: francesco.fogliamanzillo@cea.fr).

M. Śmierzchalski was with the Institute of Electronics and Telecommunications of Rennes (IETR), UMR CNRS 6164, University of Rennes 1, Rennes, France. He is currently with Atos and with CEA-LETI, Minatec Campus, Grenoble, France (e-mail: maciej.smierzchalski@cea.fr).

L. Le Coq, M. Ettorre and R. Sauleau are with the Institute of Electronics and Telecommunications of Rennes (IETR), UMR CNRS 6164, University of Rennes 1, Rennes, France, e-mail: \{laurent.lecoq; mauro.ettorre; ronan.sauleau\}@univ-rennes1.fr.

K. T. Kautio and M. Lahti are with VTT Technical Research Centre of Finland Ltd., FI-90571 Oulu, Finland (e-mail: \{markku.lahti; kari.kautio\}@vtt.fi).

J. Aurinsalo, A.E.I. Lamminen and J. Säily are with VTT Technical Research Centre of Finland Ltd., FI-02044 Espoo, Finland (e-mail: \{jouko.aurinsalo; antti.lamminen; jussi.saily\}@vtt.fi). reconfigurable radiated beams are used to cover the wide angular sectors required in the applications. Phased arrays using a tunable phase shifter for each radiating element provide the highest flexibility for beam-steering. Several transceivers implementing this beamforming scheme were presented at 60 $\mathrm{GHz}$ and beyond, both for system-in-packages (SiPs) [3], [4] and on-wafer scale [5]. However, the numerous circuit blocks and the large power consumption make these systems complex and expensive.

Multibeam antennas (MBAs) based on passive beamformers represent valid and low-cost alternatives. Circuit-based beamforming networks [6], [7] and Rotman lenses [8], [9] are effective solutions when the number of radiated beams is small. The complexity, size and loss of these networks rapidly increase with the number of input and output ports. Substrateintegrated quasi-optical beamformers [10]-[13] can mitigate these issues and achieve a good scanning performance. Since they consist of an integrated reflector system illuminated by multiple feeds, the number of radiated beams is increased by introducing additional input feeds, without increasing the overall size, which can be kept relatively compact.

Some physical limitations of passive beamformers were theoretically pointed out in [14]-[17]. White demonstrated in [15] that any passive and lossless MBAs radiate multiple, spatially-orthogonal beams. As a consequence, when the antenna comprises a single radiating aperture, the SLLs and the beam crossover levels cannot be independently controlled. Several approaches to get low SLLs and high beam crossover levels aim at radiating non-orthogonal beams using a single aperture. To this end, decoupling networks comprising resistive terminations or amplifiers [15], [17], hybrid beamswitched/steering solutions that combine phase shifters and passive beamformers [18] have been proposed. As opposed to these techniques, the split aperture decoupling method [15], [19] does not require any active devices nor additional loss. It relies on two or more separate radiating apertures designed to radiate interleaved, mutually orthogonal beams. A MBA exploiting this approach was presented in [19]. It is realized in substrate integrated waveguide (SIW) technology and comprises two specular pillbox beamformers [10], [12], each associated to a slotted waveguide array. The system achieves a $-3-\mathrm{dB}$ beam crossing level over a $\pm 40^{\circ}$ scan range and SLLs of about $-24 \mathrm{~dB}$ for the broadside beam. 


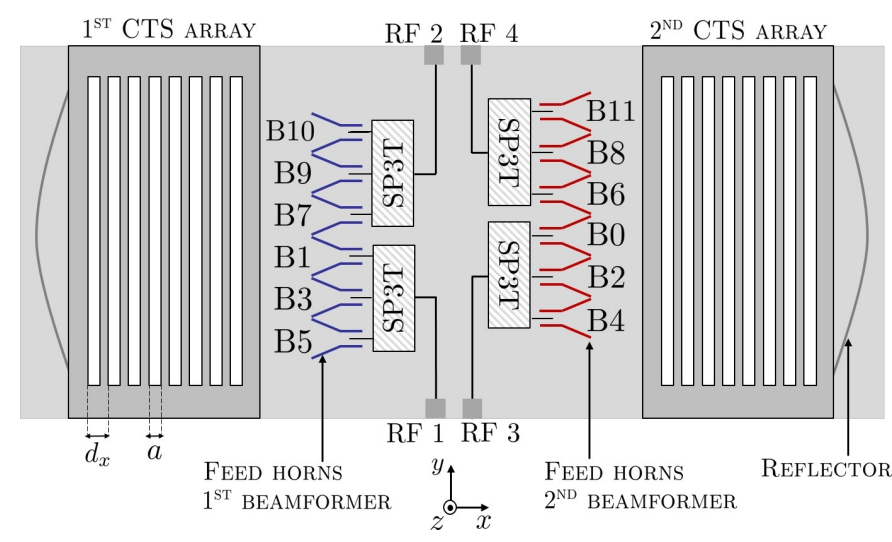

Fig. 1. Scheme of the proposed antenna system, co-integrating two multibeam parallel-fed CTS arrays excited by pillbox beamformers. The feeding horns are labeled with the symbols used for the corresponding radiated beam.

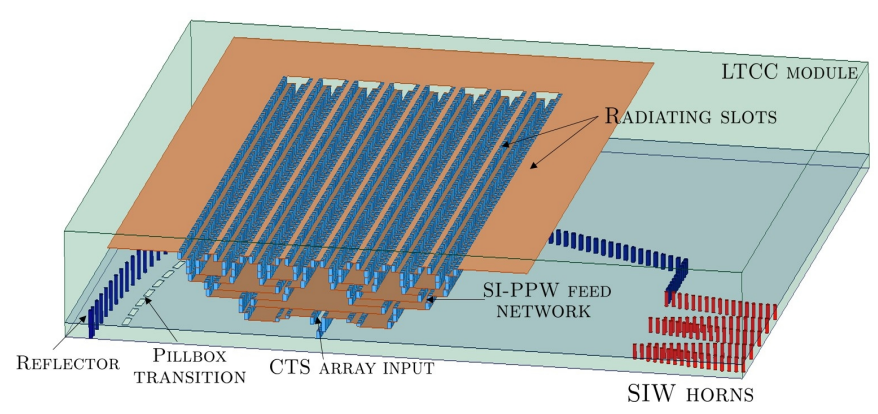

Fig. 2. Three-dimensional section of one CTS array and related pillbox beamformer.

However, this performance was demonstrated in a very narrow fractional bandwidth $(2.48 \%)$, due to the resonant nature of the waveguide arrays.

We present in this paper a novel mm-wave switched-beam antenna, with two decoupled radiating apertures, that achieves low SLLs and $-3 \mathrm{~dB}$ beam crossover over a large bandwidth (i.e. 57-66 GHz) and a wide field of view $\left( \pm 39^{\circ}\right)$. The two arrays are parallel-fed continuous transverse stub (CTS) antennas [20]-[24]. Each array is fed by a pillbox beamformer. CTS antennas consist of arrays of long slots excited by a corporate-feed network realized with parallel plate waveguides (PPWs) operating in the transverse electromagnetic (TEM) mode. The antenna system is entirely integrated in a low temperature co-fired ceramic (LTCC) module. The flatness and the reduced thickness (i.e. $3 \mathrm{~mm}$ ) of the final system, represent remarkable advantages over other beam-switching quasi-optical antennas, such as dome [25], [26] and flat [27][29] lenses. The LTCC technology is selected among other packaging solutions since it is the most suitable for realizing multilayer structures with a large number of dielectric tapes and vertical conductive paths, such as a CTS antenna. The vertical PPWs in the feed network are replaced by substrateintegrated PPWs (SIPPWs), i.e. parallel, tightly-spaced viafences, as in the fixed-beam CTS antenna presented in [24]. Each CTS array of the MBA here proposed comprises twice the number of slots (eight) and uses two less LTCC tapes, as compared to the latter work. Moreover, a network with four single-pole-triple-trow (SP3T) switches is co-integrated to electronically select the radiated beam.

The measured performance shows the great potential of the proposed technology for developing low-profile, highlyintegrated antennas and SiPs at mm-waves. To the best of the authors' knowledge, the proposed system is the first switchedbeam CTS antenna module realized in LTCC technology.

The paper is organized as follows. The antenna architecture and a preliminary system-level design are described in Section II. The design of the building blocks of the module is detailed in Section III. The experimental characterization of the prototype is presented in Section IV and the antenna performance are discussed. Conclusions are drawn in Section V.

\section{ANTENNA ARCHITECTURE AND SYSTEM-LEVEL DESIGN}

A schematic view of the antenna architecture is given in Fig. 1. The LTCC module consists of two parallel-fed CTS arrays of eight slots. Each of them is excited by a quasioptical PPW beamformer [12], [24]. A three-dimensional cross section of one of the CTS arrays and related pillbox system is presented in Fig. 2. The corporate feed network of the arrays is realized using SIPPWs. The parabolic reflectors are realized by means of tightly-spaced vias. The two beamformers comprise, in total, twelve identical SIW sectoral horns (B0 to B11), placed in the focal planes of the parabola. The antenna beam is scanned in H-plane ( $y z$-plane) by feeding one of the horns at a time and the scan angle depends on the offset of the feed from the focal point of the reflector. Only one of the two CTS arrays is excited to radiate a specific beam. A switch network with four SP3T switches is integrated on the backside and controls the beam steering. Each switch is fed by a dedicated coaxial end-launch connector to make easier the antenna characterization. The Ferro A6M-E tape system was chosen since it provides relatively low dielectric constant $\left(\epsilon_{r}=5.8\right)$ and losses $\left(\tan \delta=2.3 \times 10^{-3}\right)$, as compared to other ceramic materials.

The radiation characteristics of the antenna system primarily depends on the design of the beamformers. The main targeted specifications, to be attained between $57 \mathrm{GHz}$ and $66 \mathrm{GHz}$ are: a scan range wider than $70^{\circ}$ in H-plane, beam crossover levels, defined as the intersections among adjacent normalized beam patterns, greater than $-3 \mathrm{~dB}$ and SLLs less than $-15 \mathrm{~dB}$ for the broadside beam. The dielectric constant of the substrate complicates the achievement of the desired beam overlap level. Indeed, the direction of maximum radiation of each beam is magnified by the refraction at the interface between dielectric and air, by a factor roughly dictated by Snell's law. An adhoc tool of geometrical optics (GO) was employed to carefully analyze the design trade-offs and to define the values of the key parameters of the beamformers.

The geometry of the investigated system is shown in Fig. 3. The horns are labeled with the symbols relative to the corresponding radiated beam. The reflectors of the two specular beamformers are parabolic, with a focal length $F$ and diameter $D$ equal to the length of the radiating slots along the $y$ direction. The feeding horns are placed in the focal planes of 


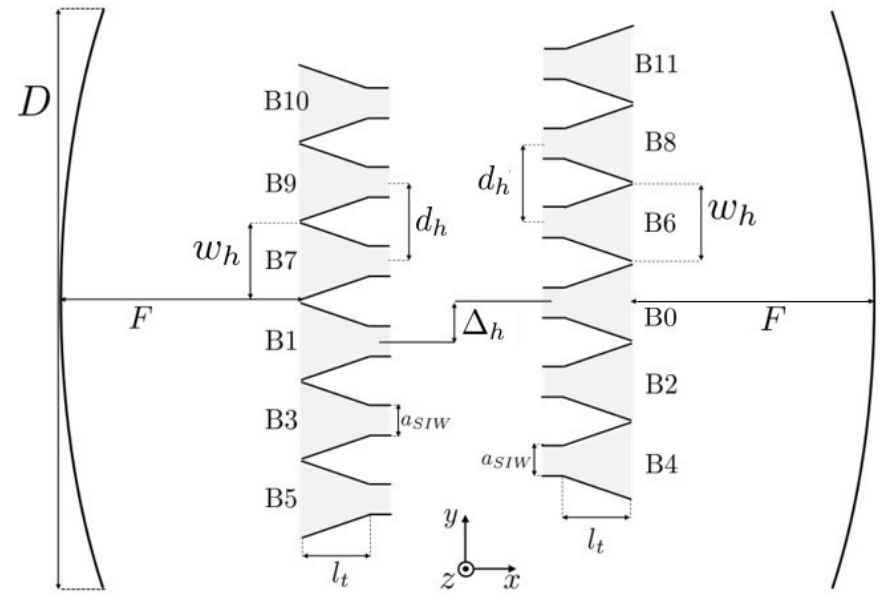

Fig. 3. Geometry of the pillbox beamformers based on parabolic reflectors illuminated by feed horns of aperture $w_{h}$. The main parameters of the system are reported.

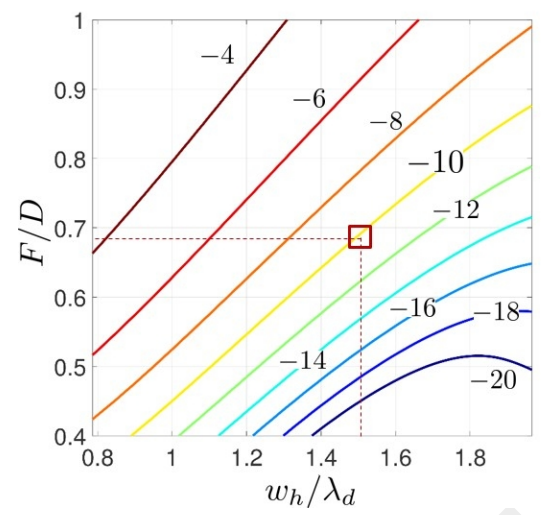

Fig. 4. Edge amplitude taper as a function of focal-to-diameter ratio $F / D$ and horn aperture $w_{h}$ normalized to the dielectric wavelength $\lambda_{d}=2 \mathrm{~mm}$. The results are computed at $61.5 \mathrm{GHz}$ for the broadside beam $\mathrm{B} 0$, using the GO analysis tool.

the respective reflectors. The aperture length of the horn along the $y$-axis is $w_{h}$, the width of the input SIW of each horn is $a_{w g}=1.6 \mathrm{~mm}$, and the length of the linear taper of the horns is $l_{t}=3.6 \mathrm{~mm}$. It is assumed that the horns relative to the same beamformer are spaced by a distance $d_{h}=w_{h}$, so that the edges of adjacent horns are tangent. The two sets of horns of the two beamformers are shifted along the $y$-axis by an offset $\Delta_{h}$. A convenient choice for this offset is $\Delta_{h}=0.5 w_{h}$. A horn in one beamformer is placed in the focus of the reflector to generate a beam pointing at boresight.

Continuous metal structures and lossless materials are considered in the GO analysis. Moreover, it is assumed that each CTS array has 8 radiating slots spaced by $d_{x}=0.3 \lambda_{0}$, where $\lambda_{0}$ is the free-space wavelength at $61.5 \mathrm{GHz}$. These choices represent a trade-off among the antenna directivity, the number of LTCC layers required to realize the corporate-feed network and the matching performance of the array, which improves for small array periodicities [22], [24].

The GO routine computes the field distribution scattered by the reflector, which excites the CTS array. The radiation patterns in H-plane are calculated from this distribution as-

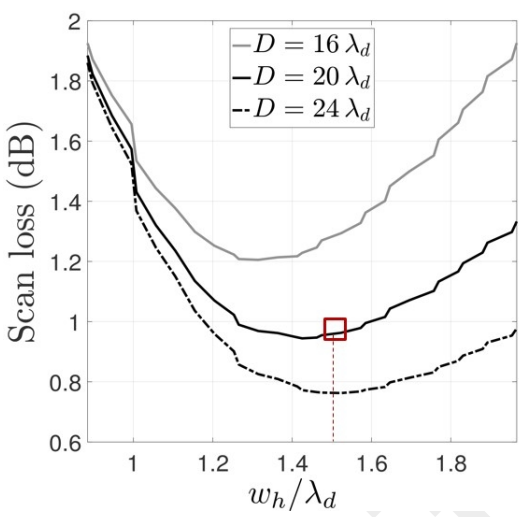

Fig. 5. Scan loss of the beam B5 at $61.5 \mathrm{GHz}$, predicted by the $\mathrm{GO}$ analysis, as a function of $w_{h} / \lambda_{d}$, when the edge-taper of the broadside beam is fixed at $-10 \mathrm{~dB}$. The offset of the horn from the focus along the $y$-axis is $2.5 w_{h}$. Different diameters $D$ of the reflectors are considered. The scan angle of B5 changes with the value of $D$.

TABLE I

FINAL DIMENSIONS (IN MILLIMETERS) OF THE GEOMETRICAL PARAMETERS IN FIG. 3

\begin{tabular}{ccccccc}
\hline$D$ & $F$ & $w_{h}$ & $d_{h}$ & $\Delta_{h}$ & $a_{S I W}$ & $l_{t}$ \\
\hline 40.3 & 27.4 & 3.0 & 3.0 & 1.5 & 1.6 & 3.6 \\
\hline
\end{tabular}

suming the aforementioned parameters for the slot arrays. The presence of the switch network and of the corporate-feed network is neglected.

An edge taper of $-10 \mathrm{~dB}$ for the broadside beam was targeted to achieve low SLLs. Figure 4 shows the contour plots of the edge taper, computed using the GO routine, at 61.5 $\mathrm{GHz}$ relative to the beam $\mathrm{B} 0$, as a function of focal-to-length ratio $F / D$ and of $w_{h} / \lambda_{d}$, i.e. the horn aperture normalized to the dielectric wavelength. A relation between these two fundamental parameters is individuated by the locus of points providing an edge taper of $-10 \mathrm{~dB}$.

The final values of $F / D$ and $w_{h}$ are set considering the characteristics of the radiated beams for several diameters of the reflectors. The scan loss at $61.5 \mathrm{GHz}$ of the beam B5, radiated by a horn placed at a distance $2.5 w_{h}$ from the focus of the reflector, are plotted in Fig. 5 as a function of $w_{h}$ for three values of $D$ and for values of $F$ providing a -10-dB-edge taper for the beam B0. The value $D=20 \lambda_{d}$ was found to be a good trade-off among scan losses, maximum directivity and size of the quasi-optical system. The values $w_{h}=1.5 \lambda_{d}$ and $F / D=0.68$ minimize the scan loss for $D=20 \lambda_{d}$. The final geometrical parameters of the beamformers are listed in Table I. For this design, the GO analysis predicts at the central frequency a maximum directivity of $23 \mathrm{dBi}$ for the broadside beam, a scan range of $\pm 39^{\circ}$ using 11 beams, with a scan loss of about $1 \mathrm{~dB}$ for the extreme beams. The horn labeled as B11 in Fig. 3 will be implemented as a dummy element and the corresponding beam, pointing at $46^{\circ}$, will not be considered. The half power beamwidth (HPBW) of beam B0 is about $7.5^{\circ}$. The targeted beam crossover level is achieved. The expected 


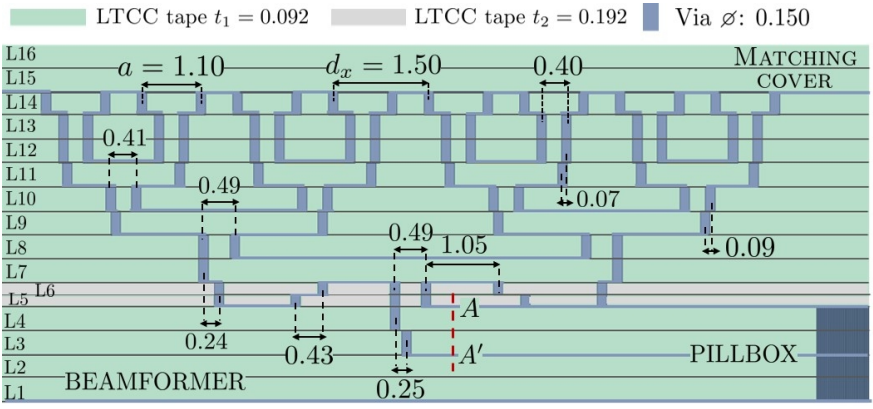

Fig. 6. Cross section of one of the two CTS arrays and its beamformer. The main geometrical parameters are reported.

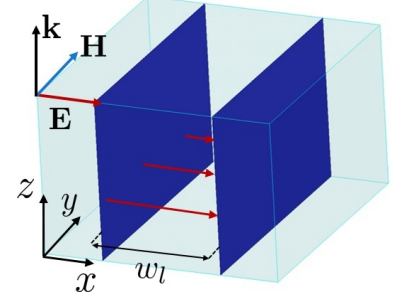

(a)

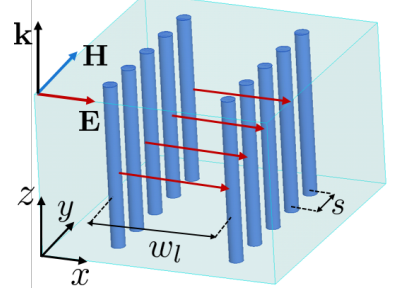

(b)
Fig. 7. Schematic view of: (a) a dielectric-filled PPW with continuous metal plates; (b) a substrate-integrated PPW (SIPPW), realized using parallel via-fences. Both waveguides support quasi-TEM modes. The polarization of quasi-TEM fields is illustrated.

first SLL at $61.5 \mathrm{GHz}$ for the broadside beam and for the beams pointing at $\pm 39^{\circ}$ are $-22.1 \mathrm{~dB}$ and $-12 \mathrm{~dB}$, respectively.

\section{PHYSICAL DESIGN}

\section{A. CTS array and pillbox beamformer}

The cross section of one of the two CTS arrays and related beamformer is shown in Fig. 6. The two arrays are identical. The stack-up includes sixteen substrate layers of two different thicknesses, whose values after co-firing are $t_{1}=92 \mu \mathrm{m}$ and $t_{2}=192 \mu \mathrm{m}$, respectively. All tapes have the same relative permittivity $\epsilon_{r}=5.8$. The metal layers and the vias were realized with a golden paste of conductivity $5 \times 10^{7} \mathrm{~S} / \mathrm{m}$. The design procedure of the quasi-optical system is similar to that presented in [12], [24]. The pillbox beamformers are designed using four LTCC tapes of thickness $192 \mu \mathrm{m}$. Each of the two stacked PPWs in a beamformer is realized with two tapes in order to reduce the ohmic losses which are proportional to the separation distance between the parallel metallic plates. In particular, an increase of $1.3 \mathrm{~dB}$ of the insertion loss was observed for the same beamformer design when only two LTCC tapes are used. A multi-slot transition contouring the integrated parabola [12], [24] couples the signal scattered by the reflector to the output PPW (layers L3-L4).

The CTS arrays were designed to achieve an input reflection coefficient less than $-15 \mathrm{~dB}$ for the broadside beam, in the $57-66-\mathrm{GHz}$ band while minimizing the number of LTCC tapes employed. To this end, a preliminary design of the slot array and of the corporate-feed network was derived assuming infinite structures along the $y$-direction and ideal PPWs, i.e. featuring continuous metal plates (see Fig. 7a). An ad-hoc

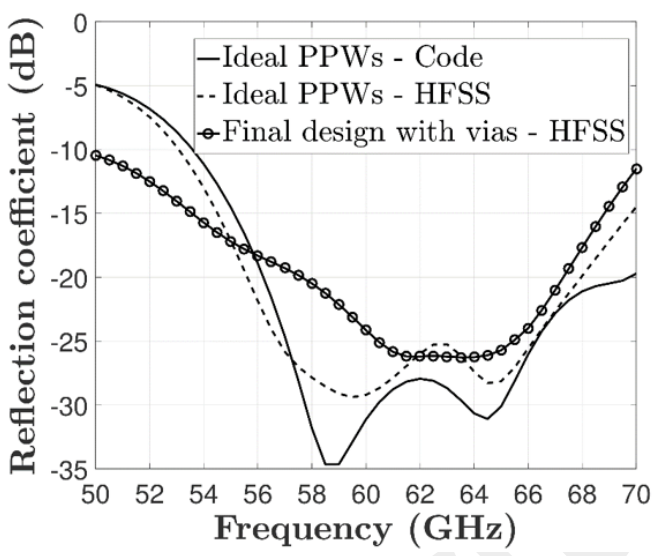

Fig. 8. Reflection coefficient at the reference plane AA' (see Fig. 6). Results computed using the ad-hoc analysis tool are compared to full-wave simulations for the preliminary design based on ideal PPWs. Simulated results relative to the final design based on vias-made SIPPWs are also shown.

numerical tool [30] developed within these hypotheses was employed to design the structure and achieve the desired input impedance. In particular, the tool combines models to compute the active impedance of the slot array [23] and to derive the scattering parameters of each component of the feed network [30], [31]. The choice of the dimensions of the components was constrained to the values allowed by the fixed thicknesses of the LTCC tapes. The two uppermost LTCC tapes (L15 and L16) of the stack-up of Fig. 6 realize a wide-angle impedance matching layer of thickness $0.384 \mathrm{~mm}$. The slot width is $a=1.1 \mathrm{~mm}$ and the slot spacing is $d_{x}=1.5 \mathrm{~mm}$. In order to reduce the number of layers, most power dividers in the feed network are based on a simple design with $90^{\circ}$ matching bends cascaded at the outputs. The input power divider, instead, features two tapes of thickness $t_{1}$ to realize impedance matching transformers and enhance the bandwidth.

Once the first-pass design is finalized, the vertical, ideal PPWs were replaced by SIPPWs consisting of parallel tightlyspaced via-fences [24], as depicted in Fig. 7b. The minimum via diameter $(0.15 \mathrm{~mm})$ and center-to-center via-spacing $(s=0.30 \mathrm{~mm})$ enabled by the technology are employed. The distance between the via-fences was finely tuned by means of full-wave simulations starting from the corresponding value defined in the preliminary design based on ideal PPWs. The final parameters are shown in Fig. 6. The reflection coefficient at section AA' is represented in Fig. 8. The results relative to the preliminary design and computed using the numerical tool tightly agree with simulations performed with Ansys HFSS. The performance achieved by the final design based on SIPPWs is similar to that of the initial design. The return loss is higher than $18.3 \mathrm{~dB}$ between $57 \mathrm{GHz}$ and $66 \mathrm{GHz}$. Material losses were not taken into account. The results were obtained by exciting the structure, infinite along the $y$-axis, with a TEM mode with uniform amplitude distribution. It has been verified that the impact of the finiteness is negligible. The proposed CTS array in LTCC technology has the double of radiating slots of the design presented in [24] and uses two layers less. This optimization was achieved in part by scaling down some 
design features. Nevertheless, this design is quite robust to technological tolerances. The input reflection coefficient is still less than $-10 \mathrm{~dB}$ when any parameter deviates of $\pm 50 \mu \mathrm{m}$ from its nominal value.

\section{B. Design of the switch network}

The switch network is designed using three LTCC tapes (L1-L3), four metal layers (M1-M4), blind and buried vias, as illustrated in Fig. 9. The input signal flows from one of the four coaxial connectors to an SP3T switch (Qorvo TGS4305-FC) through an input GCPW line. The distance between the signal line (on M1) and the ground plane (on M3) of the GCPWs is $h_{w}=0.384 \mathrm{~mm}$, corresponding to the total thickness of the tapes L1-L2 (see Fig. 9a). The effectiveness of LTCC technology in realizing low-loss vertical interconnects makes the design of the multilayer bias network straightforward. Each switch requires three bias signals. The 12 bias signals are routed from two DC connectors, soldered on M1, to the switches, using stacked blind vias in the three tapes L1-L3 and bias lines in the metal layer M4, shown in Fig. 9c. The bias lines in M4 are connected to the bias pads of the switches, in the central area of the module, using again blind vias in L1L3. The choice of routing the bias lines using M4, enabled by the LTCC process, minimizes the interference between the latter and the RF signal guided in the region bounded by M1 and $\mathrm{M} 3$.

The layout of metal layer M1 is shown in Fig. 9c. The pads of the two DC connectors can be recognized on the broad edge of the module. Some areas of the ground plane having a negligible impact on the antenna performance are meshed to improve the mechanical robustness of the module and to reduce the risk of delamination. The ground planes in M1 and M3 are connected by vias. The transmission lines of the network were realized using GCPWs to minimize ohmic and radiation losses. The long straight GCPW lines right after the coaxial-to-GCPW transition have a characteristic impedance close to $50 \Omega$. The width of their signal strips is $0.40 \mathrm{~mm}$, while the gap width is $0.2 \mathrm{~mm}$. Lines with narrower gaps $(75 \mu \mathrm{m})$ and strips $(190 \mu \mathrm{m})$ are designed to minimize the radiation losses of the $90^{\circ}$ bends and ease the interconnection with the SP3Ts. The simulated attenuation of the latter GCPW line is $0.23 \mathrm{~dB} / \mathrm{mm}$ at $60 \mathrm{GHz}$.

Figure $9 \mathrm{~d}$ shows the details of the layout around the landing pad of a switch. The datasheet of the switch reports a return loss of $8 \mathrm{~dB}$ and an insertion loss of $2.9 \mathrm{~dB}$ at $60 \mathrm{GHz}$. In order to get more accurate data in the design band, the S-parameters were extracted from measurements on-chip and on passive test structures realized on a single LTCC tape of thickness $92 \mu \mathrm{m}$. The measured reflection and transmission coefficients of the switch, in the on- and off-states, relative to the path from Port 1 to Port 3 (see Fig. 9d) are plotted in Fig. 10. The return loss is less than $10 \mathrm{~dB}$ for frequencies higher than $64 \mathrm{GHz}$, while the insertion loss is less than $3 \mathrm{~dB}$ in the band of interest. The isolation between the ports when the switch is in the off-state is higher than $24 \mathrm{~dB}$ in the design band. Similar values are obtained for the paths from Port 1 to Port 2 and to Port 4 in Fig. 9d, respectively. The actual S-parameters of the switch

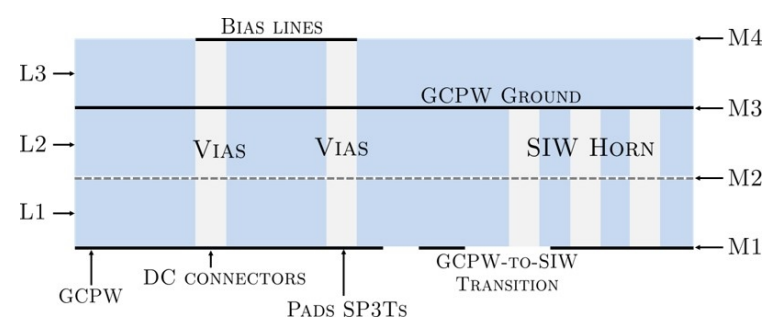

(a)

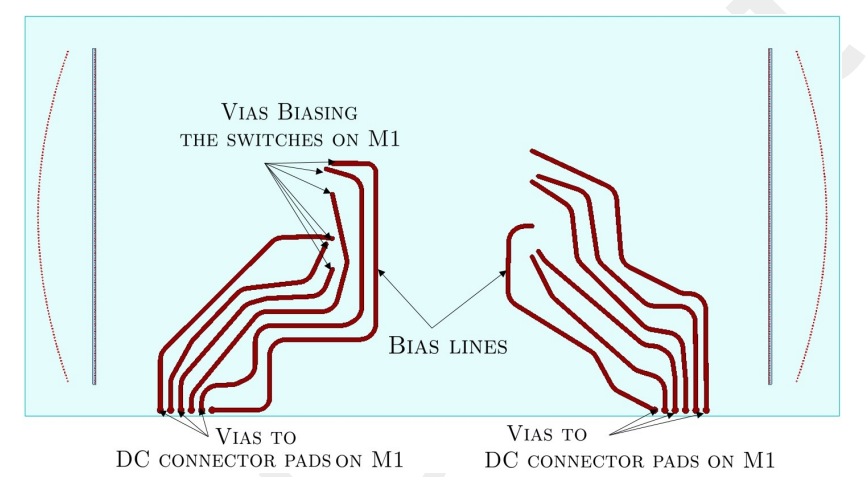

(b)

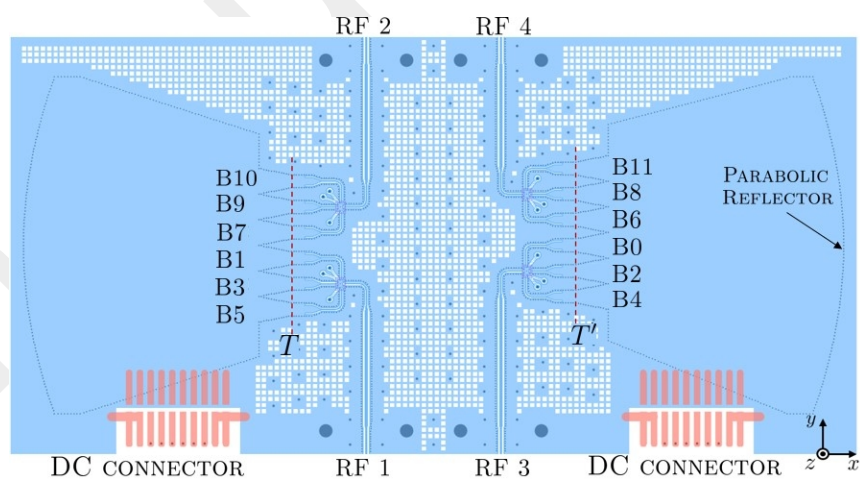

(c)

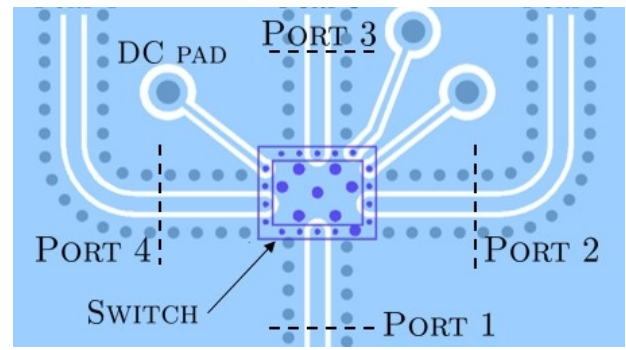

(d)

Fig. 9. (a) Schematic cross section of the switch network and DC bias routing. (b) Layout of the metal layer M4. (c) Layout of the metal layer M1. (d) Details of the layout around an SP3Ts switch.

in the prototype might differ from those here presented since, in the final design, the distance between the switches and the ground plane is $0.384 \mathrm{~mm}$.

The insertion losses of the overall switch network, from the input connectors to the integrated horns, were evaluated combining the S-parameters of the switch and the results of full-wave simulations for the microwave structures. The simulated insertion loss of the GCPW-to-SIW transitions $(0.7$ $\mathrm{dB}$ at $61.5 \mathrm{GHz}$ ) is accounted in the following results. The 


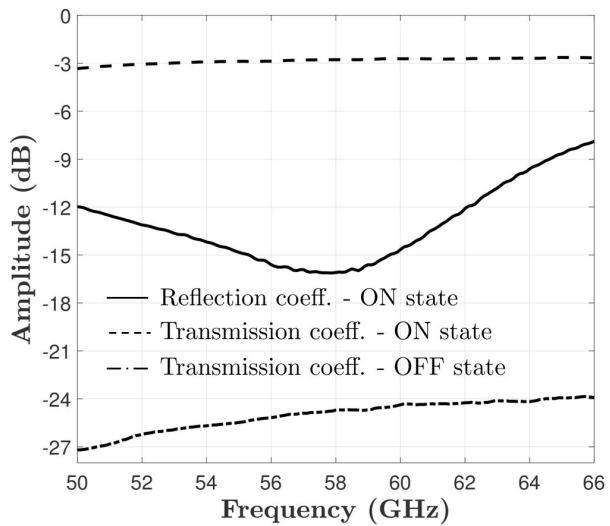

Fig. 10. Reflection and transmission coefficients of the switch, extracted from measured test structures. The path from Port 1 to Port 3 in Fig. 9d is considered.

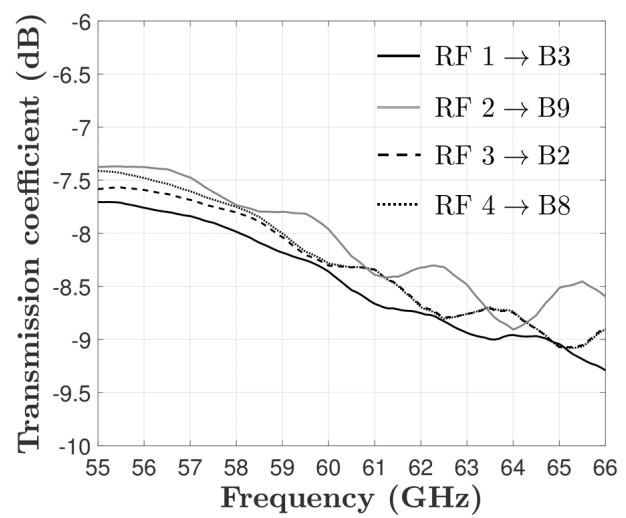

(a)

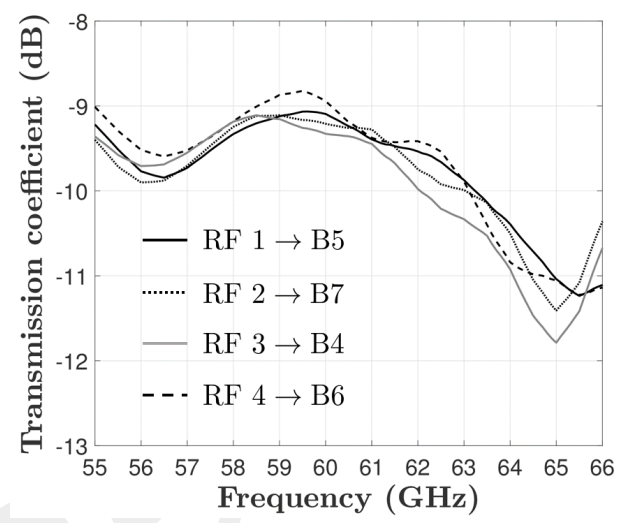

(b)

Fig. 11. Simulated transmission coefficients of the switch network at the planes $T$ and $T^{\prime}$, from the input connectors to: (a) the horns fed by the central output of the switches (Port 3 in Fig. 9d); (b) the horns fed by the lateral outputs of the switches (Port 2 and Port 4 in Fig. 9d). The legend reports the corresponding radiated beams.

design of these transitions is similar to that presented in [24]. All reflections from the quasi-optical system were neglected.

The reference planes $T$ and $T^{\prime}$ shown in Fig. 9c defines the position of the output ports, located at the input of the SIW horns. The transmission coefficients relative to the four paths from each input connector to the horns fed by the central

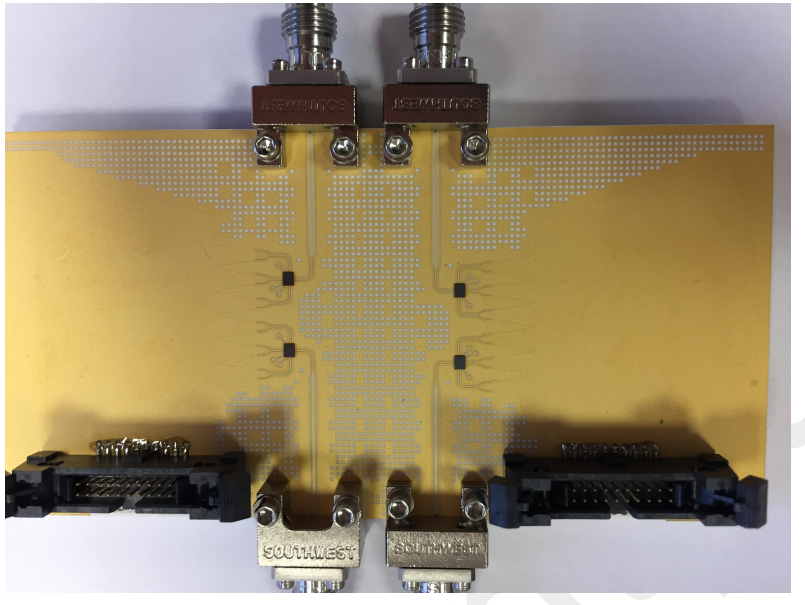

Fig. 12. Picture of the backside of the switched-beam antenna prototype. The size of the LTCC module is $98.85 \times 50 \times 3 \mathrm{~mm}^{3}$.

output lines of the corresponding switch (Port 3 in Fig. 9d) are shown in Fig. 11a. The insertion losses at $61.5 \mathrm{GHz}$ are between $8.3 \mathrm{~dB}$ and $8.7 \mathrm{~dB}$, depending on the considered path. The simulated transmission coefficients from the connectors to the horns fed by the lateral output lines of the switches (see Port 2 and Port 4) are presented in Fig. 11b. The insertion losses range between $9.5 \mathrm{~dB}$ and $9.7 \mathrm{~dB}$ at $61.5 \mathrm{GHz}$. These values are about $1 \mathrm{~dB}$ higher than those observed in the previous case, due to longer signal paths. This amplitude imbalance affects the absolute gain values of the radiated beams.

\section{ANTENNA PERFORMANCE}

\section{A. Prototype and measurements}

The antenna was fabricated and assembled at the Technical Research Centre of Finland Ltd (VTT). The Ferro A6M$\mathrm{E}$ [32] tape system provides higher strength and toughness as compared to the LTCC material used in [24]. The DC connectors were soldered on the pads and epoxy glue was applied to improve the mechanical stability and to mitigate the danger of copper peeling-off. The SP3T switches were flip-chipped on the bottom metal layer (M1 in Fig. 9a). The bottom view of the final prototype is shown in Fig. 12.

In order to control the switches, a custom bias board and two interposer cards, one for each DC connector, were developed. The bias daughter-card regulates the input voltages $( \pm 5.5 \mathrm{~V}$ and $3.3 \mathrm{~V})$ and uses multi-channel bias driver ICs (MADR-009190-000100 by Macom) to provide the required bias voltages of $-5 \mathrm{~V}$ and $1.35 \mathrm{~V}$ to the PIN-diode switches through the interposer cards. The two interposer cards are used to provide the required DC cable pinouts for the LTCC module. The bias daughter-board is plugged into a Digilent Chipkit MAX32 processor evaluation board running the lowlevel control firmware. The complete bias board is connected to a computer through a USB cable. The states of the switches, and thus the radiated beam, can be set using a terminal program communicating with the processor firmware. Figure 13 shows the setup for the measurement of the input reflection coefficients and the top face of the antenna. A single RF 


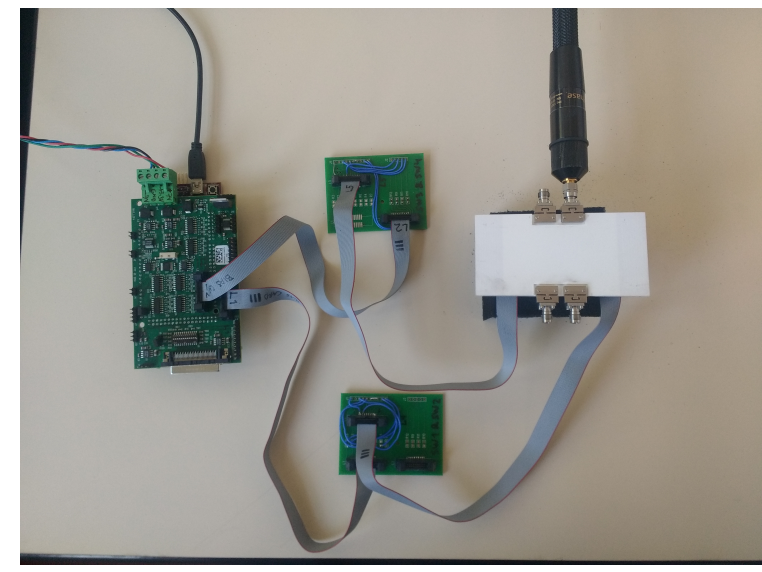

Fig. 13. Setup for the measurement of the input reflection coefficient. The custom bias board (on the left) consists of the bias daughter-card plugged into the Chipkit MAX32 processor card. Two interposer cards (in the middle) are used to route the bias signal to the two DC connectors on the antenna module. Beam switching is controlled by a computer through USB serial connection.

connector is fed by the vector network analyzer, using a precision cable. All switches were set in the off-state, except the one relative to the beam under measurement. The measured reflection coefficients for all beams are shown in Fig. 14. They are less than $-8.5 \mathrm{~dB}$, for all beams, in the $57-66 \mathrm{GHz}$ band. In the same band, the simulated reflection coefficients at the feeding horns are less than $-17.5 \mathrm{~dB}$. The observed mismatch can be attributed to reflections from the switches. Indeed, the input reflection coefficient of the stand-alone switch is relatively high. Moreover, the S-parameters considered in the design were extracted from measurements on test structures at a distance of $92 \mu \mathrm{m}$ from the ground plane. This distance is four times greater in the prototype and could modify the frequency response of the switches. Unexpected modifications of the imaginary part of the input impedance of the switch may also be introduced by the flip-chip assembly.

The radiation patterns were measured using the mm-wave compact antenna test range at the IETR [33]. Figure 15 compares measured and simulated normalized patterns $(\mathrm{H}-$ plane cut) at $61 \mathrm{GHz}$, relative to the broadside beam (B0) and to the extreme beam (B5) pointing at $39^{\circ}$. The numerical results were obtained simulating (Ansys HFSS) each of the two arrays individually, excited at the input feed horns of the beamformers. The impact of the switch-network is not accounted since a full-wave simulation of the whole structure is prohibitive in terms of computational resources. Nevertheless, simulated and experimental radiation patterns are in very good agreement. Simulations correctly predict the beamwidths and the scan angles.

The H-plane cut of the measured realized gain patterns across the band are shown for all beams in Fig. 16. A scan range of about $\pm 39^{\circ}$ is covered from $57 \mathrm{GHz}$ to $66 \mathrm{GHz}$ using eleven overlapping beams. The amplitude imbalance of the switch-network affects the peak gain values of the beams. The maximum realized gain at $61.5 \mathrm{GHz}$ ranges from $11.2 \mathrm{dBi}$ to $13.7 \mathrm{dBi}$ over the scan range. The SLLs of the broadside beam at $61.5 \mathrm{GHz}$ are less than $-21 \mathrm{~dB}$.

The frequency behavior of the antenna is very stable over

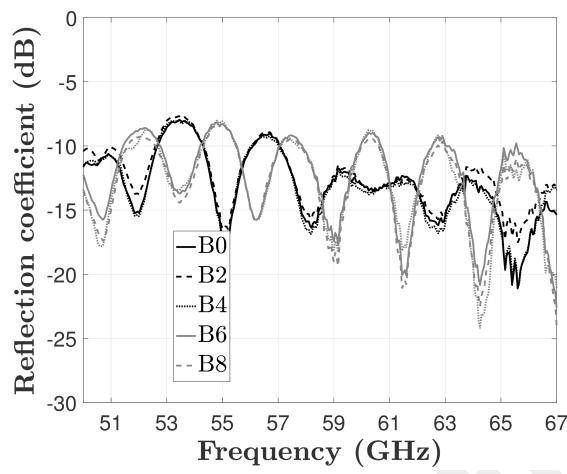

(a)

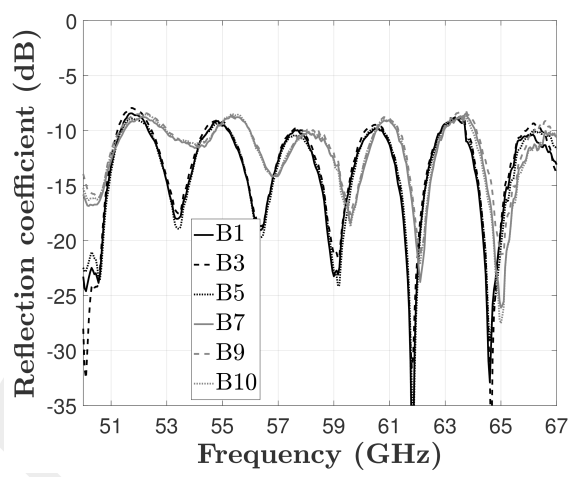

(b)

Fig. 14. Measured reflection coefficients at the input connectors: (a) RF1 and RF2; (b) RF3 and RF4. The corresponding radiated beams are indicated in the legend.

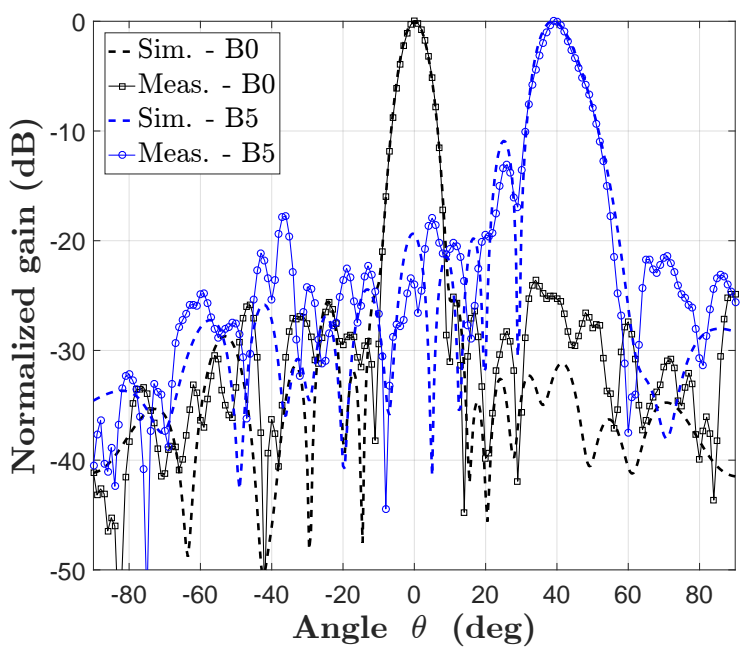

Fig. 15. Simulated and measured normalized H-plane patterns at $61 \mathrm{GHz}$ for the broadside beam (B0) and the beam B5 pointing at $39^{\circ}$.

the band of interest and also at lower frequencies. Figure 17 shows the contour plot of the normalized far-field pattern $(\mathrm{H}-$ plane cut) as a function of frequency and elevation angles. Three different beams are presented. The directions of maximum gain vary less than $1^{\circ}$ around the mean value between $57 \mathrm{GHz}$ and $66 \mathrm{GHz}$ for all beams except those pointing at about $\pm 39^{\circ}$. The scan angles of the latter ones vary of $\pm 1^{\circ}$. 


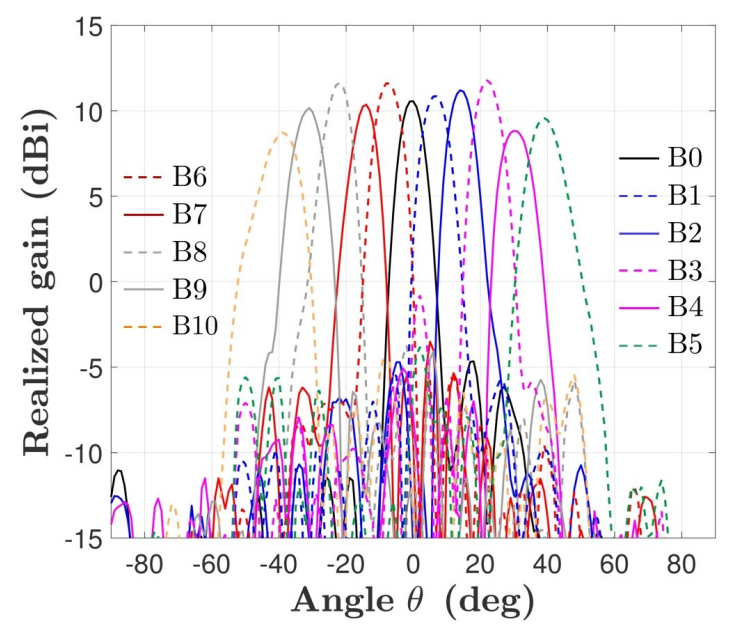

(a)

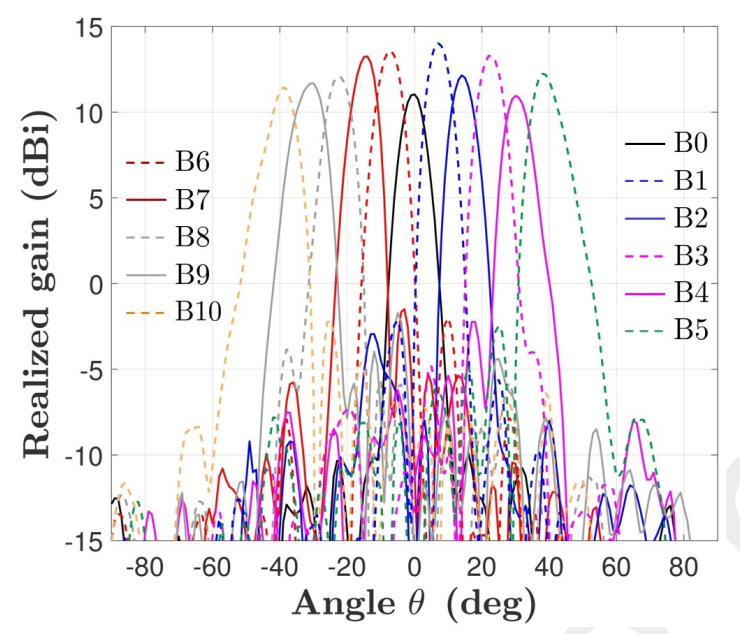

(b)

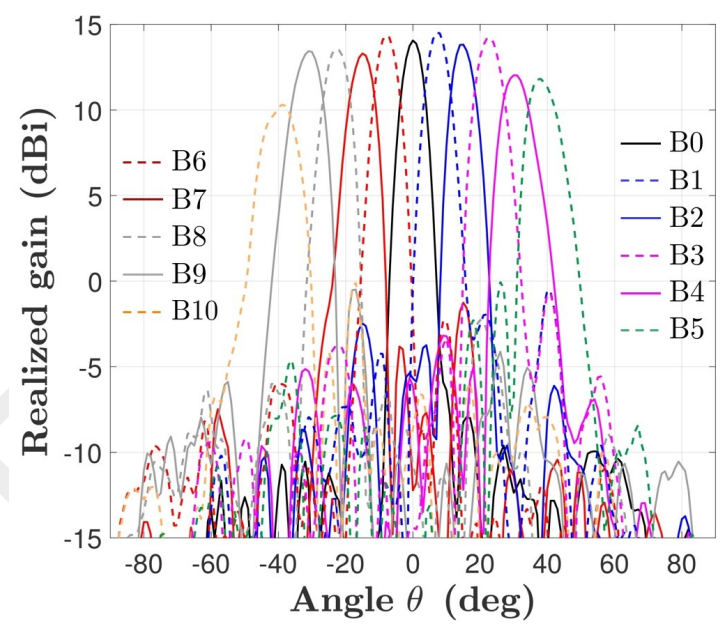

(c)

Fig. 16. Measured realized gain patterns in the $\mathrm{H}$-plane at: (a) $57 \mathrm{GHz}$, (b) $61.5 \mathrm{GHz}$, (c) $65 \mathrm{GHz}$.

The beams pointing at directions close to boresight exhibit a $-3-\mathrm{dB}$ beamwidth of about $7.5^{\circ}$. The HPBW increases with
TABLE II

ChARACTERISTICS OF THE BEAMS IN FIG. 17 IN THE 57-66-GHz BAND

\begin{tabular}{ccccc}
\hline Beam & Scan angle & HPBW & Max. SLL & X-pol level \\
\hline B0 & $0^{\circ} \pm 0.4^{\circ}$ & $7.4^{\circ} \pm 0.2^{\circ}$ & $-15.2 \mathrm{~dB}$ & $-22.5 \mathrm{~dB}$ \\
\hline B2 & $14.8^{\circ} \pm 0.5^{\circ}$ & $7.7^{\circ} \pm 0.4^{\circ}$ & $-13.7 \mathrm{~dB}$ & $-21.0 \mathrm{~dB}$ \\
\hline B5 & $38.7^{\circ} \pm 1^{\circ}$ & $10.5^{\circ} \pm 0.9^{\circ}$ & $-11.0 \mathrm{~dB}$ & $-18.8 \mathrm{~dB}$ \\
\hline
\end{tabular}

the scan angle up to about $10.5^{\circ}$ for the outermost beams.

A slight asymmetry of the broadside beam pattern can be observed in Fig. 17a. The SLLs are higher for positive elevation angles. This effect can be attributed to the finite isolation of the switches. Part of the signal at the input of the switch reaches the two horns B2 and B4 (see Fig. 1) which generate a spurious radiation perturbing the expected pattern due to the excitation of the horn B0. The measured and simulated radiation patterns at $63 \mathrm{GHz}$ are shown in Fig. 18. At this frequency, the simulated results obtained assuming a perfect isolation of the switch, i.e. exciting only the horn B0, do not match the measurements outside the main lobe. Instead, the simulation accounting for the finite isolation of the switches (dashed line in Fig. 18) fairly predicts the positions and the levels of the sidelobes measured at $15^{\circ}$ and $30^{\circ}$. These data were computed as the weighted sum of the complex values of the far-fields obtained by feeding each horn individually (B0, B2 and B4). The weighting coefficients were determined using the scattering parameters of the switch and full-wave simulations of the lines between the outputs of the switch and the horns.

The key characteristics of the beams shown in Fig. 17 are summarized in Table II. The SLLs of the broadside beam are less than $-15.2 \mathrm{~dB}$ between $57 \mathrm{GHz}$ and $66 \mathrm{GHz}$, and have an average value of $-18.3 \mathrm{~dB}$ in the same band. The SLLs of the outermost beams in the scan range are less than $-11.0 \mathrm{~dB}$. All beams exhibit low cross-polarization (X-pol) levels in the entire frequency band.

Measurements confirm the effectiveness of the split-aperture decoupling technique in achieving overlapping beams with low SLLs. The -3-dB contours of the normalized patterns in $\mathrm{H}-$ plane are plotted as functions of elevation angle and frequency in Fig. 19. All pairs of adjacent beams cross at an amplitude level higher than $-3 \mathrm{~dB}$ in the considered frequency range.

\section{B. Loss budget}

The maximum realized gain values vary between $9.4 \mathrm{dBi}$ and $14.7 \mathrm{dBi}$ in the $57-66-\mathrm{GHz}$ band, depending on the radiated beam. The gain drop of each beam is less than $3 \mathrm{~dB}$ in the band. The switch network introduces the major part of the overall loss. In particular, the input lines routing the endlaunch connectors to the switches represent the most relevant sourced of loss. The electrical length of these lines is about $13 \lambda_{d}$. A detailed analysis of the losses of the module when radiating the broadside beam is proposed in Table IV-B, at the central frequency $(61.5 \mathrm{GHz})$. The expected directivity, extracted from simulations on the CTS array excited at the feed horn, is $23.2 \mathrm{dBi}$, while the measured realized gain is $11.0 \mathrm{dBi}$. 


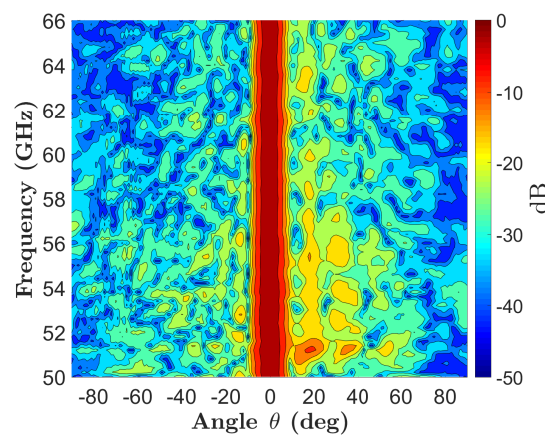

(a)

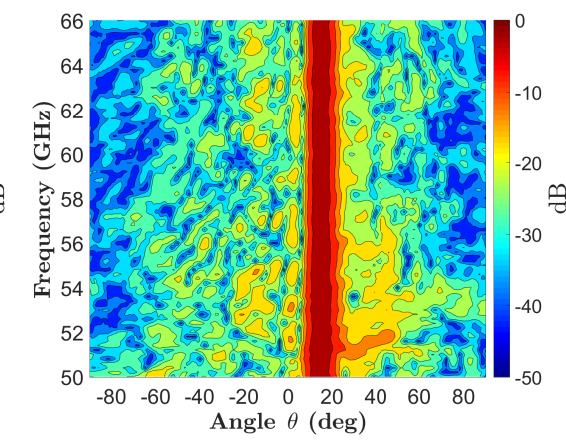

(b)

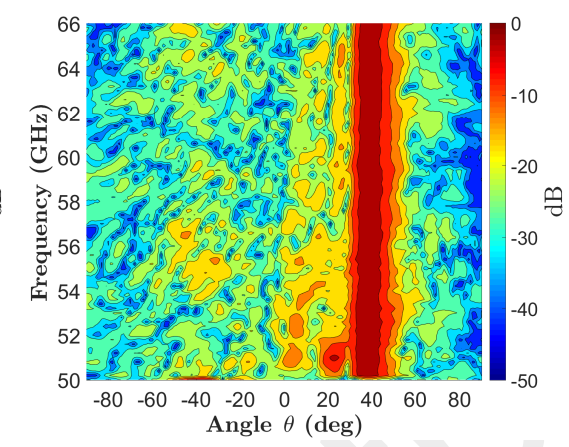

(c)

Fig. 17. Normalized H-plane gain patterns as a function of elevation angle and frequency for three beams: (a) B0 pointing at $0^{\circ}$; (b) B2 pointing at about $14^{\circ}$; (c) B5 pointing at about $39^{\circ}$.

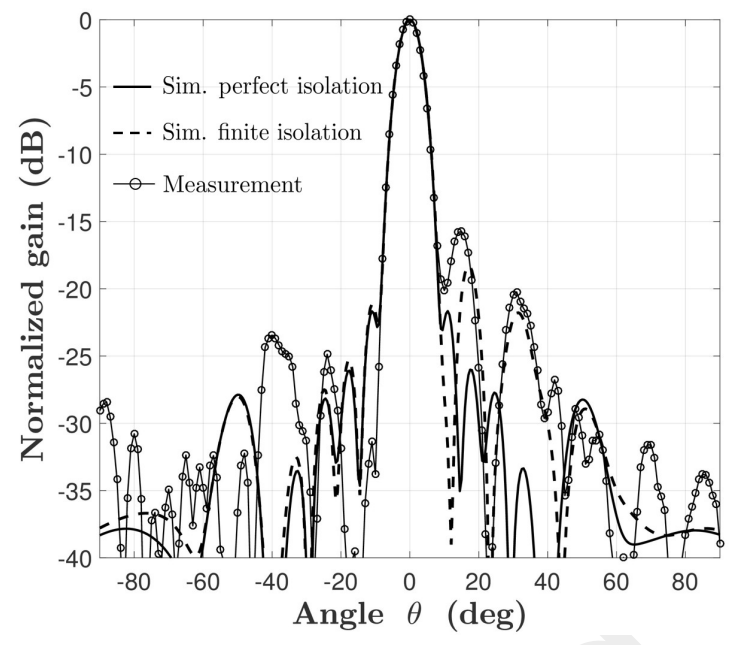

Fig. 18. Simulated and measured normalized radiation patterns of the broadside beam at $63 \mathrm{GHz}$ (H-plane cut). The simulated patterns are computed assuming either a perfect isolation of the switch (solid line) or the measured isolation (dashed line) shown in Fig. 10.

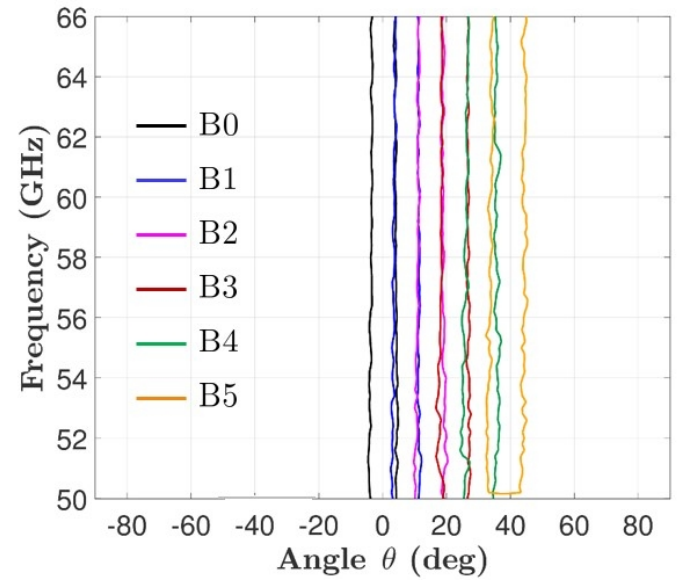

Fig. 19. -3-dB contour plots of the radiation patterns (H-plane cut) against frequency. The beams pointing at non-negative scan angles are shown.

A total loss of $12.2 \mathrm{~dB}$ is estimated. The contributions of the
TABLE III

LOSS BUDGET FOR THE BROADSIDE BEAM AT $61.5 \mathrm{GHZ}$

\begin{tabular}{ccc}
\hline \multicolumn{2}{c}{ Simulated directivity } & $23.2 \mathrm{dBi}$ \\
\hline \multicolumn{2}{c}{ Measured realized gain } & $11.0 \mathrm{dBi}$ \\
\hline \multirow{2}{*}{$\begin{array}{c}\text { Simulated loss of the } \\
\text { switch-network }\end{array}$} & Input lines & $6.2 \mathrm{~dB}$ \\
\cline { 2 - 3 } & Switch & $2.8 \mathrm{~dB}$ \\
\hline Sim. loss of the CTS antenna-to-SIW transition & $0.7 \mathrm{~dB}$ \\
\hline
\end{tabular}

TABLE IV

PERFORMANCE OF STATE-OF-THE-ART PASSIVE PHASE SHIFTERS

\begin{tabular}{ccccc}
\hline Ref. & Technology & Freq. range (GHz) & Phase range & Insertion loss (dB) \\
\hline$[34]$ & 65-nm CMOS & $57-66$ & $90^{\circ}$ (3-bit) & $5.69 \pm 1.22$ \\
\hline$[35]$ & 65-nm CMOS & $57-66$ & $360^{\circ}$ (4-bit) & $8.7 \pm 1.7$ \\
\hline$[36]$ & $90-\mathrm{nm} \mathrm{CMOS}$ & $57-64$ & $360^{\circ}$ (4-bit) & $12.8 \pm 2.8$ \\
\hline$[37]$ & 130-nm BiCMOS & $58-64$ & $360^{\circ}$ (4-bit) & $9.95 \pm 0.35$ \\
\hline
\end{tabular}

main blocks of the module were evaluated by means of fullwave simulations. The simulated insertion loss of the switchnetwork, from the input connector to the feed horn B0, is 9.7 $\mathrm{dB}$. Specifically, the insertion loss from the input connector to the switch is $6.2 \mathrm{~dB}$ and that of the switch is $2.8 \mathrm{~dB}$. The transition from the GCPW line at the output of the switch to the SIW horn introduces a loss of $0.7 \mathrm{~dB}$. The dielectric and ohmic losses of the CTS array and related beamformer are $2.5 \mathrm{~dB}$. It is worth noting that the input GCPW lines, responsible for more than $6 \mathrm{~dB}$ of loss, were introduced for testing purposes, in order to excite each switch from an endlaunch connector located on the broad edge of the module.

\section{Discussion and comparison with the state of the art}

The proposed system can be easily designed with a single RF input and the GCPW lines can be greatly shortened. The antenna loss would be then reduced, as observed in Section IV-B. A single-pole-four-throw (SP4T) can be used to control the four SP3Ts switches. The insertion loss of an SP4T switch 
TABLE V

COMPARISON WITH STATE-OF-THE-ART PASSIVE MULTIBEAM V-BAND ANTENNAS

\begin{tabular}{ccccccc}
\hline Ref. & Antenna type & Freq. range $(\mathbf{G H z})$ & Peak gain $(\mathbf{d B i})$ & Field of view & Beam crossover level \\
\hline$[6]$ & Butler matrix + waveguide array & $59-63.5$ & 26.25 & $\pm 43^{\circ}, 4$ beams & $-10 \mathrm{~dB}$ \\
\hline$[8]$ & Rotman lens + patch array & $57-65$ & n.a & $\pm 30^{\circ}, 5$ beams & $-4 \mathrm{~dB}$ \\
\hline$[26]$ & Patch array + shaped dielectric lens & $52-68$ & 18.4 & $\pm 35^{\circ}, 5$ beams & $-3 \mathrm{~dB}$ & $30 \times 130 \times 3.9$ \\
\hline$[28]$ & Patch array + transmitarray & $59.5-66$ & 23.5 & $\pm 6.3^{\circ}, 5$ beams & $-3 \mathrm{~dB}$ & n.a., bare lens: $15 \times 15 \times 7.5$ \\
\hline$[29]$ & Waveguide array + planar lens & $57-66$ & 18.4 & $\pm 54^{\circ}, 5$ beams & $-8.5 \mathrm{~dB}$ & $25 \times 25 \times 13.7$ w/o switch matrix \\
\hline This work & CTS array + pillbox beamformer & $57-66$ & 14.7 & $\pm 39^{\circ}, 11$ beams & $-3 \mathrm{~dB}$ \\
\hline
\end{tabular}

Qorvo TGS4305-FC is about $3 \mathrm{~dB}$ at $60 \mathrm{GHz}$ [25]. Therefore, an antenna module comprising four SP3T switches, an SP4T switch and a single RF input close to the switches, e.g. an SMP connector or a waveguide, exhibits an overall loss of about $9 \mathrm{~dB}$ at $61.5 \mathrm{GHz}$. This estimation is derived from the values reported in Table III, neglecting the loss of the GCPW lines and considering $3 \mathrm{~dB}$ of insertion loss for the additional SP4T switch. Though significant, the loss of this antenna architecture is lower than the typical values observed for phased arrays. Since the proposed antenna module does not include any amplifier, the typical losses of phased arrays based on passive phase shifters will be considered as a reference for comparison. The antenna presented in this work radiates 11 beams. A theoretical phase-resolution of 3.4 bits is necessary for generating the same number of beams in a standard phased array. Therefore, 3-bit and 4-bit phase shifters are examined. Table IV shows the insertion loss of state-of-the-art passive phase shifters in V-band. It can be observed that a stand-alone 4-bit passive phase shifter introduces losses in the order of or greater than the insertion loss estimated for the proposed switched-beam antenna architecture with single RF input (i.e. $9 \mathrm{~dB}$ ). In addition to the insertion loss of the phase shifters, the losses of the power distribution network and of the radiating elements should be accounted to fairly estimate the overall loss of a phased array architecture. The passive beam-switching antenna solution achieves a significant efficiency improvement as compared to linear phased arrays with the same field of view. On the other hand, phased arrays attain flexible beam steering and finer angular resolution within the scan range.

The features and performance of the switched-beam CTS array system are compared in Table $\mathrm{V}$ to other passive multibeam antennas successfully demonstrated at $60 \mathrm{GHz}$. It emerges that the proposed system generates the greatest number of beams. State-of-the-art passive antenna modules presented in the open literature rarely radiate more than five beams, which leads either to a limited field of view or to low beam crossover levels. These limitations are essentially due to the complexity of beamforming circuits [6] and lenses [8], which rapidly grows with the number of radiated beams and lead to bulky and lossy designs. Spatiallyfed array architectures, such as shaped dielectric lenses [26] and transmitarrays [28], [29], offer a simple beam-switching mechanism and achieve high gain. However, they require large focal distances which preclude their integration in a monolithic system-in-package up to sub-millimeter waves. In conclusion, the substrate-integrated and low-profile CTS array module finely covers a wide field of view thanks to the split aperture decoupling design, over a $15 \%$ fractional bandwidth, at the expenses of a relatively large occupied area.

\section{CONCLUSION}

A $60-\mathrm{GHz}$ electronically-agile multibeam antenna module in LTCC technology has been presented. The system features two broadband, parallel-fed, substrate-integrated CTS arrays excited by pillbox beamformers and a switch-network controlling the beam-steering. The design of the different components, performed with the aid of dedicated numerical tools, has been detailed. The final system was realized in a monolithic multilayer LTCC module whose size is $98.85 \times 50 \times 3 \mathrm{~mm}^{3}$. The antenna prototype covers with eleven beams a scan range of about $\pm 39^{\circ}$ between $57 \mathrm{GHz}$ and $66 \mathrm{GHz}$. It achieves at the same time low SLLs and beam crossing levels higher than -3 $\mathrm{dB}$. The SLLs of the broadside and outermost beams are less than $-15.2 \mathrm{~dB}$ and $-11.0 \mathrm{~dB}$, respectively, in the band. The realized gain values of the beams at $61.5 \mathrm{GHz}$ are between $11.2 \mathrm{dBi}$ and $13.7 \mathrm{dBi}$ and vary less than $3 \mathrm{~dB}$ in the band. The insertion loss of the switch-network is about $9.7 \mathrm{~dB}$ at $61.5 \mathrm{GHz}$, due to the long input interconnects, included to ease the measurements.

The proposed flat antenna achieves a continuous coverage of wider scan ranges and lower SLLs as compared to state-of-theart passive multibeam antennas, at the expenses of a reduced aperture efficiency. This architecture represents a cost-effective and low-power alternative to phased arrays in applications requesting one-dimensional beam-steering.

Future studies could investigate CTS antennas-in-package integrating power amplifiers to increase the radiated power. Moreover, the design of larger arrays achieving higher gain and aperture efficiency could be investigated. The maximum number of layers enabled by the technology limits the gain. Nevertheless, standard LTCC processes allow the designers to use four more tapes which are enough to double, at least, the number of elements of each CTS array (from 8 to 16).

A more accurate design of the switch-network is also envisioned. An SP4T switch controlling the four SP3T switches will make it possible to excite the system from a single RF input. Delay lines should be introduced at the central outputs of the SP3T switches to reduce the amplitude imbalance at the feeding horns. The scan range can be further extended using shaped reflectors and arranging the feeds of each beamformer along optimized focal curves. 


\section{ACKNOWLEDGMENT}

This work was supported by the European Union Seventh Framework Programme (FP7/2007-2013) under grant agreement $n^{\circ} 619563$ (MiWaveS).

\section{REFERENCES}

[1] A. Ghosh, T. A. Thomas, M. C. Cudak, R. Ratasuk, P. Moorut, F. W. Vook, T. S. Rappaport, G. R. MacCartney, S. Sun, and S. Nie, "Millimeter-wave enhanced local area systems: a high-data-rate approach for future wireless networks," IEEE J. Sel. Areas Commun. vol. 32, no. 6, pp. 1152-1163, Jun. 2014.

[2] C. Dehos, J. L. González, A. D. Domenico, D. Ktnas, and L. Dussopt, "Millimeter-wave access and backhauling: the solution to the exponential data traffic increase in $5 \mathrm{G}$ mobile communications systems?" IEEE Commun. Mag., vol. 52, no. 9, pp. 88-95, Sep. 2014.

[3] E. Cohen, M. Ruberto, M. Cohen, O. Degani, S. Ravid, and D. Ritter, "A CMOS bidirectional 32-element phased-array transceiver at $60 \mathrm{GHz}$ with LTCC antenna," IEEE Trans. Microw. Theory Techn., vol. 61, no. 3, pp. 1359-1375, Mar. 2013.

[4] B. H. Ku, P. Schmalenberg, O. Inac, O. D. Gurbuz, J. S. Lee, K. Shiozaki, and G. M. Rebeiz, "A 77-81-GHz 16-element phased-array receiver with $\pm 50^{\circ}$ beam scanning for advanced automotive radars," IEEE Trans. Microw. Theory Techn., vol. 62, no. 11, pp. 2823-2832, Nov. 2014.

[5] S. Zihir, O. D. Gurbuz, A. Kar-Roy, S. Raman, and G. M. Rebeiz, "60$\mathrm{GHz} 64-$ and 256-elements wafer-scale phased-array transmitters using full-reticle and subreticle stitching techniques," IEEE Trans. Microw. Theory Techn., vol. 64, no. 12, pp. 4701-4719, Dec. 2016.

[6] K. Tekkouk, J. Hirokawa, R. Sauleau, M. Ettorre, M. Sano, and M. Ando, "Dual-layer ridged waveguide slot array fed by a Butler matrix with sidelobe control in the 60-GHz band," IEEE Trans. Antennas Propag., vol. 63, no. 9, pp. 3857-3867, Sep. 2015.

[7] T. Djerafi, N. J. G. Fonseca, and K. Wu, "Broadband substrate integrated waveguide $4 \times 4$ Nolen matrix based on coupler delay compensation," IEEE Trans. Microw. Theory Techn., vol. 59, no. 7, pp. 1740-1745, Jul. 2011.

[8] W. Lee, J. Kim, C. S. Cho, and Y. J. Yoon, "Beamforming lens antenna on a high resistivity silicon wafer for $60 \mathrm{GHz}$ WPAN," IEEE Trans. Antennas Propag., vol. 58, no. 3, pp. 706-713, Mar. 2010.

[9] A. Attaran, R. Rashidzadeh, and A. Kouki, " $60 \mathrm{GHz}$ low phase error Rotman lens combined with wideband microstrip antenna array using LTCC technology," IEEE Trans. Antennas Propag., vol. 64, no. 12, pp. 5172-5180, Dec. 2016.

[10] T. Teshirogi, Y. Kawahara, A. Yamamoto, Y. Sekine, N. Baba, and M. Kobayashi, "Dielectric slab based leaky-wave antennas for millimeter-wave applications," in Proc. IEEE Antennas Propag. Soc. Int. Symp., vol. 1, Jul. 2001, pp. 346-349.

[11] Y. J. Cheng, W. Hong, and K. Wu, "Millimeter-wave substrate integrated waveguide multibeam antenna based on the parabolic reflector principle," IEEE Trans. Antennas Propag., vol. 56, no. 9, pp. 3055-3058, Sep. 2008.

[12] M. Ettorre, R. Sauleau, and L. Le Coq, "Multi-beam multi-layer leakywave SIW pillbox antenna for millimeter-wave applications," IEEE Trans. Antennas Propag., vol. 59, no. 4, pp. 1093-1100, Apr. 2011.

[13] Z. L. Ma and C. H. Chan, "A novel surface-wave-based high-impedance surface multibeam antenna with full azimuth coverage," IEEE Trans. Antennas Propag., vol. 65, no. 4, pp. 1579-1588, Apr. 2017.

[14] J. L. Allen, "A theoretical limitation on the formation of lossless multiple beams in linear arrays," IRE Trans. Antennas Propag., vol. 9, no. 4, pp. 350-352, Jul. 1961.

[15] W. D. White, "Pattern limitations in multiple-beam antennas," IRE Trans. Antennas Propag., vol. 10, no. 4, pp. 430-436, Jul. 1962.

[16] S. Stein, "On cross coupling in multiple-beam antennas," IRE Trans. Antennas Propag., vol. 10, no. 5, pp. 548-557, Sep. 1962.

[17] E. DuFort, "Optimum low sidelobe high crossover multiple beam antennas," IEEE Trans. Antennas Propag., vol. 33, no. 9, pp. 946-954, Sep. 1985.

[18] C. C. Chang, R. H. Lee, and T. Y. Shih, "Design of a beam switching/steering Butler matrix for phased array system," IEEE Trans. Antennas Propag., vol. 58, no. 2, pp. 367-374, Feb. 2010.

[19] K. Tekkouk, M. Ettorre, E. Gandini, and R. Sauleau, "Multibeam pillbox antenna with low sidelobe level and high-beam crossover in SIW technology using the split aperture decoupling method," IEEE Trans. Antennas Propag., vol. 63, no. 11, pp. 5209-5215, Nov. 2015.
[20] W. W. Milroy, "The continuous transverse stub (CTS) array: basic theory, experiment, and application," in Proc. Antenna Appl. Symp., vol. 2, Sep. 1991, pp. 253-283.

[21] _ "Compact, ultra-wideband, antenna feed architecture comprising a multistage, multilevel network of constant reflection-coefficient components," U.S. Patent 6075 494, Jun. 13, 2000.

[22] M. Ettorre, F. Foglia Manzillo, M. Casaletti, R. Sauleau, L. Le Coq, and N. Capet, "Continuous transverse stub array for Ka-band applications," IEEE Trans. Antennas Propag., vol. 63, no. 11, pp. 4792-4800, Nov. 2015.

[23] F. Foglia Manzillo, M. Ettorre, M. Casaletti, N. Capet, and R. Sauleau, "Active impedance of infinite parallel-fed continuous transverse stub arrays," IEEE Trans. Antennas Propag., vol. 63, no. 7, pp. 3291-3297, Jul. 2015.

[24] F. Foglia Manzillo, M. Ettorre, M. S. Lahti, K. T. Kautio, D. Lelaidier, E. Seguenot, and R. Sauleau, "A multilayer LTCC solution for integrating 5G access point antenna modules," IEEE Trans. Microw. Theory Techn., vol. 64, no. 7, pp. 2272-2283, Jul. 2016.

[25] J. Ala-Laurinaho, J. Aurinsalo, A. Karttunen, M. Kaunisto, A. Lamminen, J. Nurmiharju, A. V. Räisänen, J. Säily, and P. Wainio, "2-D beam-steerable integrated lens antenna system for 5G E-band access and backhaul," IEEE Trans. Microw. Theory Techn., vol. 64, no. 7, pp. 2244-2255, Jul. 2016.

[26] A. Artemenko, A. Maltsev, A. Mozharovskiy, A. Sevastyanov, V. Ssorin, and R. Maslennikov, "Millimeter-wave electronically steerable integrated lens antennas for WLAN/WPAN applications," IEEE Trans. Antennas Propag., vol. 61, no. 4, pp. 1665-1671, Apr. 2013.

[27] L. Di Palma, A. Clemente, L. Dussopt, R. Sauleau, P. Potier, and P. Pouliguen, "Circularly-polarized reconfigurable transmitarray in Kaband with beam scanning and polarization switching capabilities," IEEE Trans. Antennas Propag., vol. 65, no. 2, pp. 529-540, Feb. 2017.

[28] L. Dussopt, A. Moknache, J. Säily, A. Lamminen, M. Kaunisto, J. Aurinsalo, T. Bateman, and J. Francey, "A V-band switched-beam linearly polarized transmit-array antenna for wireless backhaul applications," IEEE Trans. Antennas Propag., vol. 65, no. 12, pp. 6788-6793, Dec. 2017.

[29] M. Imbert, J. Romeu, M. Baquero-Escudero, M. T. Martinez-Ingles, J. M. Molina-Garcia-Pardo, and L. Jofre, "Assessment of LTCCbased dielectric flat lens antennas and switched-beam arrays for future 5G millimeter-wave communication systems," IEEE Trans. Antennas Propag., vol. 65, no. 12, pp. 6453-6473, Dec. 2017.

[30] F. Foglia Manzillo, "Wideband and flat multibeam antenna solutions for ultrafast communications in millimeter band," Ph.D. dissertation, University of Rennes 1, Rennes, France, 2017.

[31] F. Foglia Manzillo, R. Sauleau, N. Capet, and M. Ettorre, "Mode matching analysis of an E-plane $90^{\circ}$ bend with a square step in parallel plate waveguide," IEEE Antennas Wireless Propag. Lett., vol. 16, pp. $2187-2190,2017$.

[32] A6M/A6M-E High Frequency LTCC Tape System, Ferro, 112015.

[33] L. Le Coq, B. Fuchs, T. Kozan, S. Burgos, and P. O. Iversen, "IETR millimeter-wave compact antenna test range implementation and validation," in 9th Eur. Conf. Antennas Propag. (EuCAP), May 2015, pp. $1-5$.

[34] F. Meng, K. Ma, K. S. Yeo, S. Xu, C. C. Boon, and W. M. Lim, "Miniaturized 3-bit phase shifter for $60 \mathrm{GHz}$ phased-array in $65 \mathrm{~nm}$ CMOS technology," IEEE Microwave and Wireless Components Letters, vol. 24, no. 1, pp. 50-52, Jan. 2014.

[35] C. W. Byeon and C. S. Park, "A low-loss compact 60-GHz phase shifter in 65-nm CMOS," IEEE Microw. Wireless Compon. Lett., vol. 27, no. 7, pp. 663-665, Jul. 2017.

[36] Y.-C. Chiang, W.-T. Li, J.-H. Tsai, and T.-W. Huang, "A 60-GHz digitally controlled 4-bit phase shifter with 6-ps group delay deviation," in Proc. IEEE MTT-S Int. Microw. Symp. Digest, Jun. 2012, pp. 1-3.

[37] T. W. Li and H. Wang, "A millimeter-wave fully integrated passive reflection-type phase shifter with transformer-based multi-resonance loads for $360^{\circ}$ phase shifting," IEEE Trans. Circuits Syst. I: Reg. Papers, vol. 65, no. 4, pp. 1406-1419, Apr. 2018. 